\title{
MICROBIAL CELL
}

FACTORIES

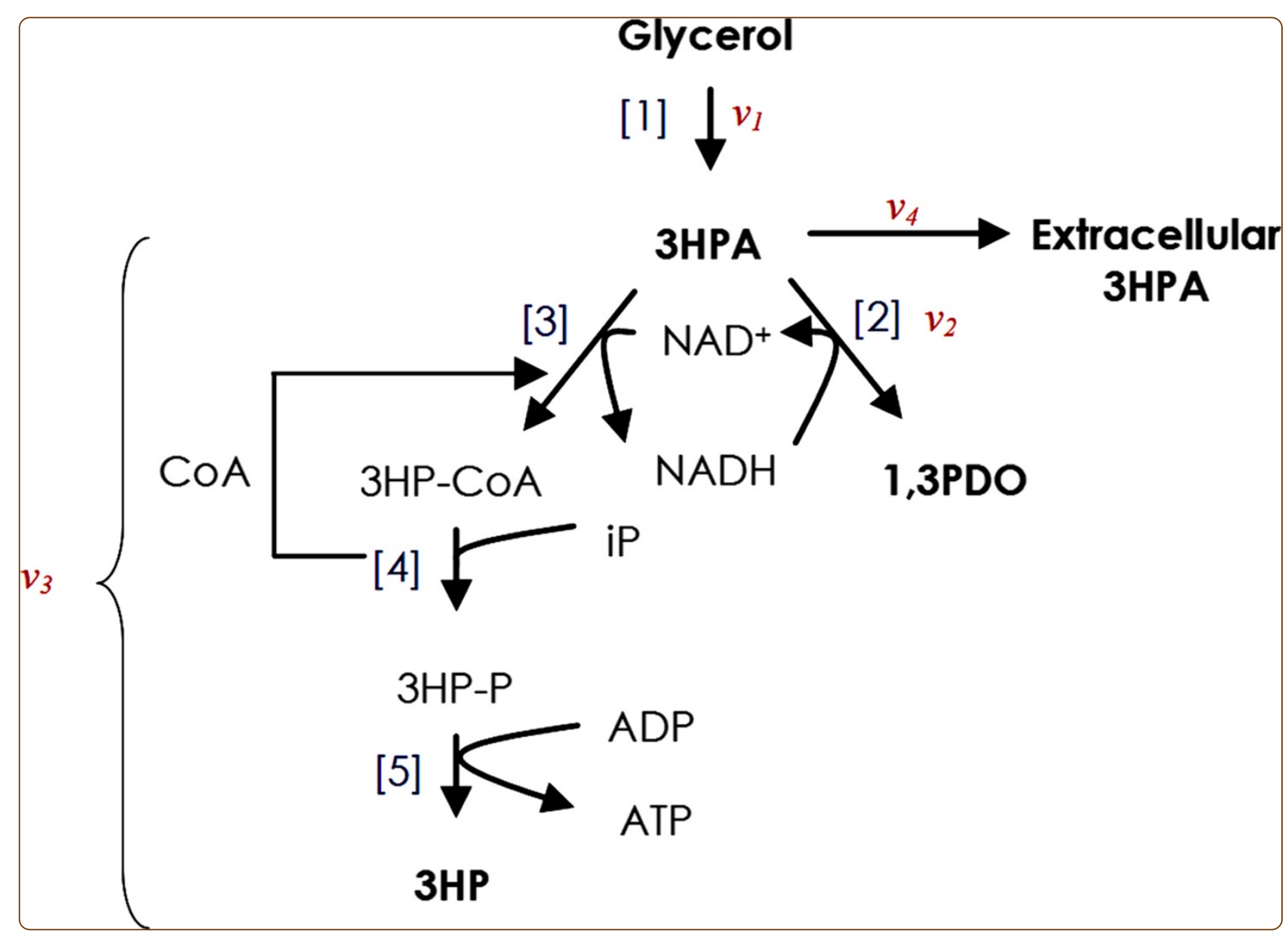

Flux analysis of the Lactobacillus reuteri propanediol-utilization pathway for production of 3-hydroxypropionaldehyde, 3-hydroxypropionic acid and 1,3-propanediol from glycerol

Dishisha et al. 


\title{
Flux analysis of the Lactobacillus reuteri propanediol-utilization pathway for production of 3-hydroxypropionaldehyde, 3-hydroxypropionic acid and 1,3-propanediol from glycerol
}

Tarek Dishisha $^{1{ }^{* \dagger}}$, Luciana P Pereyra ${ }^{1+}$, Sang-Hyun Pyo ${ }^{1}$, Robert A Britton ${ }^{2}$ and Rajni Hatti-Kaul ${ }^{1}$

\begin{abstract}
Background: Lactobacillus reuteri converts glycerol to 3-hydroxypropionic acid (3HP) and 1,3-propanediol (1,3PDO) via 3-hydroxypropionaldehyde (3HPA) as an intermediate using enzymes encoded in its propanediol-utilization (pdu) operon. Since 3HP, 1,3PDO and 3HPA are important building blocks for the bio-based chemical industry, $L$. reuteri can be an attractive candidate for their production. However, little is known about the kinetics of glycerol utilization in the Pdu pathway in L. reuteri. In this study, the metabolic fluxes through the Pdu pathway were determined as a first step towards optimizing the production of 3HPA, and co-production of 3HP and 1,3PDO from glycerol. Resting cells of wild-type (DSM 20016) and recombinant (RPRB3007, with overexpressed pdu operon) strains were used as biocatalysts.
\end{abstract}

Results: The conversion rate of glycerol to 3HPA by the resting cells of L. reuteri was evaluated by in situ complexation of the aldehyde with carbohydrazide to avoid the aldehyde-mediated inactivation of glycerol dehydratase. Under operational conditions, the specific 3HPA production rate of the RPRB3007 strain was 1.9 times higher than that of the wild-type strain (1718.2 versus $889.0 \mathrm{mg} / \mathrm{gcDw}_{\mathrm{C}}$ h, respectively). Flux analysis of glycerol conversion to 1,3PDO and 3HP in the cells using multi-step variable-volume fed-batch operation showed that the maximum specific production rates of 3HP and 1,3PDO were 110.8 and $93.7 \mathrm{mg} / \mathrm{g}_{\mathrm{CD} w} \cdot \mathrm{h}$, respectively, for the wild-type strain, and 179.2 and $151.4 \mathrm{mg} / \mathrm{gcDw}_{\mathrm{C}} \mathrm{h}$, respectively, for the RPRB3007 strain. The cumulative molar yield of the two compounds was $\sim 1 \mathrm{~mol} / \mathrm{mol}$ glycerol and their molar ratio was $\sim 1 \mathrm{~mol}_{3 \mathrm{HP}} / \mathrm{mol}_{1,3 \mathrm{PDO}}$. A balance of redox equivalents between the glycerol oxidative and reductive pathway branches led to equimolar amounts of the two products.

Conclusions: Metabolic flux analysis was a useful approach for finding conditions for maximal conversion of glycerol to $3 \mathrm{HPA}, 3 \mathrm{HP}$ and 1,3PDO. Improved specific production rates were obtained with resting cells of the engineered RPRB3007 strain, highlighting the potential of metabolic engineering to render an industrially sound strain. This is the first report on the production of $3 \mathrm{HP}$ and 1,3PDO as sole products using the wild-type or mutant L. reuteri strains, and has laid ground for further work on improving the productivity of the biotransformation process using resting cells.

Keywords: Lactobacillus reuteri, 3-hydroxypropionaldehyde, 3-hydroxypropionic acid, 1,3-propanediol, Biodiesel glycerol, Flux analysis, Biorefinery, Biochemicals

\footnotetext{
* Correspondence: Tarek.Dishisha@biotek.lu.se

${ }^{\dagger}$ Equal contributors

'Department of Biotechnology, Center for Chemistry and Chemical

Engineering, Lund University, SE-221 00 Lund, Sweden

Full list of author information is available at the end of the article
} 


\section{Background}

Recent years have seen a growing interest in shifting from fossil- to a more renewable feedstock based on biomass for the production of chemicals and materials with a lower carbon footprint $[1,2]$. In order to match the efficiency and flexibility of the petrochemical industry, a number of platform chemicals have been identified for the bio-based industry that would serve as building blocks for a range of other products [1,2]. Among these are 3hydroxypropionaldehyde (3HPA), 3-hydroxypropionic acid (3HP) and 1,3-propanediol (1,3PDO) [1,2]. While there is no existing industrial production of the former two chemicals [3,4], 1,3PDO has been produced industrially from fossil-based propylene and ethylene, respectively, by Degussa and Shell processes (in both processes, 3HPA is formed as an intermediate) $[5,6]$.

$3 \mathrm{HPA}$ is a potential platform for several high-volume products like acrolein, 3HP, 1,3PDO, malonic acid, acrylamide and acrylic acid [3,7-9], and can also be used as an antimicrobial agent (reuterin) in food and health industries [3]. 3HP, besides being an important precursor for acrylic acid [10], is a potential building block for the production of propionilactone, biodegradable polyesters and oligomers, and other products for food and cosmetic industries [10-12]. 1,3PDO is incorporated in copolyesters and advanced polymers, and used as ingredient in wood paints, anti-freeze, adhesives and laminates $[10,13,14]$. Microbial production offers an attractive route for obtaining these chemicals from bio-based resources, as seen by the several studies reported using wild-type and engineered bacteria. Production of 1,3PDO from sugar using engineered Escherichia coli is indeed done on large scale $[15,16]$, and scale up of $3 \mathrm{HP}$ production is also being attempted [17].

The large volume of glycerol obtained as a by-product of biodiesel as well as bioethanol and soap manufacture [18-21], represents a potentially useful carbon substrate for production of 3HPA, 3HP and 1,3PDO. Several members of the genera Clostridia, Lactobacilli, Klebsiella, and Citrobacter can use glycerol as an electron acceptor yielding $1,3 \mathrm{PDO}$ via $3 \mathrm{HPA}$ as an intermediate. Recently, the feasibility of simultaneous production of $3 \mathrm{HP}$ and 1,3PDO using recombinant strains of Klebsiella pneumonia, Lactobacillus reuteri and E. coli has been reported [4,22-26]. The simple separation of these two compounds makes this route very attractive [27]. However, despite the high titers and production rates reported, most of these production routes share the common problem of relatively low yields and large amounts of by-products (lactic acid, ethanol, butanol, succinic acid, and acetic acid, among others) with high structural similarity to the desired products, which complicated the downstream processing $[4,23,24,26]$. Further metabolic engineering of $K$. pneumonia aimed at minimizing lactic acid production was successful, but the cumulative yield of 3HP and 1,3PDO was only $0.77 \mathrm{~mol} / \mathrm{mol}$ glycerol [26].

L. reuteri is a very attractive candidate for the production of 3HPA, 3HP and 1,3PDO. In contrast to the opportunistic pathogen $K$. pneumonia, it has a "generally recognized as safe" status and is also used as a probiotic, hence restrictions on scaling up for industrial production are minimal. L. reuteri uses glycerol only as an electron acceptor and not as a carbon source for growth, which ensures the absence of undesired by-products in the reaction mixture. Transformation of glycerol by growing $L$. reuteri results in $1,3 \mathrm{PDO}$ as the main product. The resting cells, on the other hand, convert glycerol to 3HPA catalyzed by glycerol dehydratase $(\mathrm{GDH})$, while 1,3PDO and 3HP are formed in small quantities as by-products. Due to the inhibitory effect of 3HPA, the process is rapidly terminated if the aldehyde is not trapped as a complex with sodium bisulfite, semicarbazide or carbohydrazide [28-31]. The ability of $L$. reuteri to synthesize adenosylcobalamin (vitamin B12), an essential co-factor for glycerol dehydratase, is an additional economical advantage for its use as production host [32].

Bioconversion of 3HPA to 1,3PDO and 3HP occurs through a reductive and an oxidative pathway, respectively $[28,29]$; the enzymes involved in these reactions are encoded in the propanediol-utilization $(p d u)$ operon. The production of $3 \mathrm{HP}$ alone or in a mixture with $1,3 \mathrm{PDO}$ as main products using a wild-type $L$. reuteri has however not been successful [22,33], mainly due to the accumulation to toxic levels of the intermediate 3 HPA $[22,28]$ and its inhibitory effect on one of the enzymes of the oxidative pathway [34], as well as the diversion of glycerol to dihydroxyacetone (DHA) catalyzed by a glycerol dehydrogenase [33]. The co-production of 3HP and 1,3PDO was only possible after the gene encoding the enzyme glycerol dehydrogenase was knocked out [22]. Despite the increasing interest and research on the utilization of $L$. reuteri in industrial biotechnology, there is only fragmentary information regarding metabolic fluxes within the Pdu pathway and conditions for the co-production of $3 \mathrm{HP}$ and 1,3PDO as main end products.

In the present study, metabolic flux analysis (MFA), a technique that has been widely used for quantification of fluxes, determination of nodal rigidity and metabolic bottlenecks, and assisting the choice of the proper metabolic engineering strategy [35-37], was employed to gain a better understanding of the kinetics of glycerol utilization and 3HPA distribution into reductive and oxidative pathways in $L$. reuteri. This was done with the aim to determine conditions for achieving maximal yields of the desired products while overcoming the inhibitory/toxic effects. The determination of these fluxes is challenging due to the toxic nature of the intermediate 3HPA, the 
compartmentalization of some intermediates (3HPA and $3 \mathrm{HP}-\mathrm{CoA}$ ) [38], and the co-factors recycling between the different steps, affecting the overall dynamics of the system. The flux of glycerol to 3HPA was analyzed using batch mode of operation by trapping the aldehyde as a complex, while the fluxes to $3 \mathrm{HP}$ and 1,3PDO were measured using a multi-step fed-batch mode of operation. The study was performed with two L. reuteri strains: wild-type and an engineered strain (RPRB3007) [39] in which the genes encoded in the $p d u$ operon were overexpressed.

\section{Results and discussion}

\section{Mechanism of glycerol biotransformation and choice of} biotransformation conditions with whole cells of $L$. reuteri

The expected pathway for the conversion of glycerol to $1,3 \mathrm{PDO}$ and $3 \mathrm{HP}$ by $L$. reuteri is illustrated in Figure 1. It is initiated by the dehydration of glycerol to 3HPA in a reaction catalyzed by a B12-dependent glycerol/diol dehydratase (GDH) [33]. Further conversion of 3HPA to $1,3 \mathrm{PDO}$ is catalyzed by 1,3-propanediol oxidoreductase (PduQ) and a putative alcohol dehydrogenase [40]. This reaction is coupled to the regeneration of one mole of $\mathrm{NAD}^{+}$per mole 1,3PDO produced, allowing the glycerol to be continuously utilized by the growing cells as an electron acceptor for conversion of NADH generated during sugar metabolism and cell growth [41]. In contrast, when resting cells are used, this reaction will proceed only until all the NADH molecules available in the cells are consumed. At this point, the role of the oxidative pathway is very important through which $3 \mathrm{HPA}$ is oxidized in a

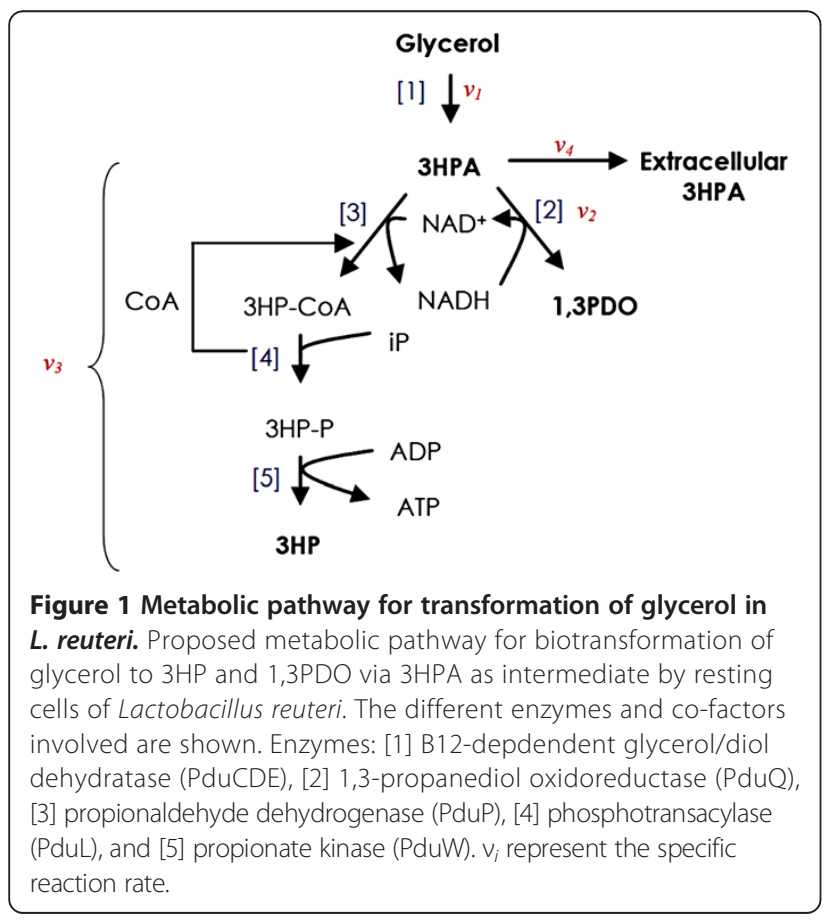

three-step reaction catalyzed by CoA-dependent propionaldehyde dehydrogenase (PduP), phosphotransacylase (PduL) and propionate kinase (PduW), respectively, to $3 \mathrm{HP}$ with 3HP-CoA and 3HP-phosphate as intermediates, and utilizing $\mathrm{NAD}^{+}$to yield $\mathrm{NADH}$ resulting in a balance of redox equivalents $[33,42]$. The overall balance of reducing equivalents would result in the equimolar production of the hydroxyacid and the diol. Furthermore, the Coenzyme A (CoA) required for synthesis of $3 \mathrm{HP}-\mathrm{CoA}$ in the PduP-catalyzed step is released later in the PduL-catalyzed reaction allowing continuous regeneration of these two co-factors. The last step of the conversion of $3 \mathrm{HPA}$ to $3 \mathrm{HP}$ yields one mole of ATP per mole of $3 \mathrm{HP}$ formed, which makes the reaction thermodynamically favorable [27], and could be a reason for continuity even when resting cells are used. The ATP generated during this step might be used for maintenance of cells [22] or for active transport of 3HP outside the cell [43]. Also, it could be utilized for reactivation (via a reactivase) of the inactivated glycerol dehydratase in a process that requires ATP, $\mathrm{Mg}^{+2}$ ions and adenosylcobalamin [44].

Compared to other species that can grow on glycerol, L. reuteri cannot use glycerol as a carbon source due to the lack of dihydroxyacetone kinase for conversion of DHA to dihydroxyacetone phosphate prior to metabolism via the glycolysis and phosphoketolase pathways $[45,46]$. This implies that no by-products will be formed during glycerol bioconversion, hence simplifying the downstream processing that is suggested to be one of the main factors influencing the cost of production of $3 \mathrm{HP}$ by recombinant E. coli [47].

Based on the above information, the process using resting cells of $L$. reuteri was selected to analyze the metabolic flux of glycerol to 3HPA, and the flux distribution around 3 HPA to the reductive and oxidative pathway branches. $L$. reuteri cells used for the studies were grown in the culture medium containing $5 \mathrm{~g} / \mathrm{L}$ 1,2-propanediol (1,2PDO), which (or glycerol) is important for activating the expression of the genes encoding enzymes and structural proteins required for glycerol metabolism [48] and also for triggering the formation of metabolosomes required for entrapment of the produced aldehyde and its subsequent conversion to the CoA-derivative through the membrane-bound PduP [33]. Addition of 1,2PDO results in a larger increase in GDH activity than with the same concentration of glycerol [33].

Cell growth was continued until the late stationary phase $(11 \mathrm{~h})$ when all the glucose $(40 \mathrm{~g} / \mathrm{L})$ and 1,2PDO were consumed, and yielding a final cell density of 3.1 $\mathrm{g}_{\mathrm{CDW}} / \mathrm{L}, 14.3 \pm 0.4 \mathrm{~g} / \mathrm{L}$ lactic acid, $2.5 \pm 0.3 \mathrm{~g} / \mathrm{L}$ acetic acid and $6.6 \pm 1.6 \mathrm{~g} / \mathrm{L}$ ethanol. Also $3.0 \pm 0.4 \mathrm{~g} / \mathrm{L} n$-propanol was obtained from 1,2PDO. The resulting active biomass was utilized as a whole-cell catalyst for biotransformation experiments. 


\section{Metabolic flux of glycerol in L. reuteri resting cells using batch mode of operation in the presence of 3HPA scavenger} According to our earlier experiments, resuspension of the $L$. reuteri cells, cultivated as described above, in a glycerol solution $(200-400 \mathrm{mM})$ was suitable for the production of $3 \mathrm{HPA}$ at a high purity and concentration, but loss of cell viability and enzymatic activity was observed within $2 \mathrm{~h}[28,49]$. This could be attributed to different factors, including toxicity of the aldehyde to the cells and enzymatic machineries [49], and the inactivation of the glycerol dehydratase enzyme due to breakdown of the $\mathrm{Co}-\mathrm{C}$ bond in the co-factor adenosylcobalamin [44].

The biocatalyst life span is significantly extended by in situ complexation of the aldehyde with bisulfite, carbohydrazide or semicarbazide [28,29]; the latter two form more stable complexes with 3HPA [29]. Hence, carbohydrazide was chosen as a $3 \mathrm{HPA}$ scavenger to minimize the toxic effect of the aldehyde on the cells and hence allow determination of the true conversion rate of glycerol to 3HPA. pH 7 was selected for determining the glycerol uptake and 3HPA accumulation rates based on the earlier report revealing the optimal $\mathrm{pH}$ of production of $3 \mathrm{HPA}$ to be shifted from pH 5 to 7 in the presence of carbohydrazide [29]. Under operational conditions, the conversion of $50 \mathrm{~g} / \mathrm{L}$ glycerol was achieved within $6 \mathrm{~h}$ using $6 \mathrm{~g}_{\mathrm{CDw}} / \mathrm{L}$ of the wild-type strain (Figure 2A). The overall volumetric$\left(Q_{3 H P A}\right)$ and specific $3 \mathrm{HPA}$ production rates $\left(q_{3 H P A}\right)$ were $4.3 \pm 0.1 \mathrm{~g} / \mathrm{L} . \mathrm{h}$ and $889.0 \pm 65.6 \mathrm{mg} / \mathrm{g}_{\mathrm{CDW}} \cdot \mathrm{h}$, respectively. When RPRB3007 strain was used, the specific productivity was $1.9 \mathrm{x}$ higher $\left(1718.2 \pm 98.3 \mathrm{mg} / \mathrm{g}_{\mathrm{CDw}} \cdot \mathrm{h}\right)$ than in the wild-type strain and complete consumption of glycerol was achieved within $3 \mathrm{~h}$ with formation of $26.2 \pm 1.3 \mathrm{~g} / \mathrm{L}$ $3 \mathrm{HPA}$ at a rate of $8.7 \mathrm{~g} / \mathrm{L}$.h as a carbohydrazide complex (Figure 2B). Simultaneously, $5.8 \mathrm{~g} / \mathrm{L} \mathrm{1,3PDO}$ and $6.9 \mathrm{~g} / \mathrm{L}$ $3 \mathrm{HP}$ were also obtained. In both strains, glycerol uptake and $3 \mathrm{HPA}$ production was characterized by a fast rate for the first $30 \mathrm{~min}$ followed by a slower linear rate thereafter (Figure 2 and Table 1).

\section{Flux analysis and flux distribution through oxidative and reductive pathways in $L$. reuteri resting cells}

Bioconversion of glycerol to $1,3 \mathrm{PDO}$ and $3 \mathrm{HP}$ by $L$. reuteri is subject to different inhibitory mechanisms, which need to be avoided to achieve maximum yield and productivity. 3HPA besides being toxic to the cells is also inhibitory to the PduP enzyme at a concentration exceeding $0.6 \mathrm{~g} / \mathrm{L}$ [34]. Moreover, high glycerol and 1,3PDO concentrations inhibit glycerol dehydratase activity [49]. A controlled variablevolume fed-batch operation with glycerol as a limiting substrate was designed, in which the feed was applied at a rate that allowed consumption of the entire glycerol and formation of $3 \mathrm{HP}$ and 1,3PDO as end products. To determine the maximum flux around 3HPA towards 3HP and $1,3 \mathrm{PDO}$, the glycerol feeding rate was increased stepwise to a level that maximized the fluxes $v_{2}$ and $v_{3}$ (Figure 1). At this point, accumulation of 3HPA occurred (flux $v_{4}$ ) at a concentration that was low enough not to cause toxic or inhibitory effects. Since the availability of co-factors produced during cell growth phase could result in apparent rates in the initial hours of fedbatch biotransformation that are higher than the actual rates, data from the first 10 hours of the bioconversion was not utilized in the calculation of the fluxes.

When the experiment was conducted at $\mathrm{pH} 5$, no accumulation of the intermediate aldehyde was observed in the wild-type strain during operation in batch $(1 \mathrm{~h})$ and fedbatch at $0.6 \mathrm{~g} / \mathrm{h}$ glycerol (Figure $3 \mathrm{~A}$ ). Complete conversion of glycerol to $3 \mathrm{HP}$ and 1,3PDO as the main end products was observed. The link between the oxidative and reductive branches through the co-factor regeneration reaction created a rigid node around 3HPA. The flux split ratio around $3 \mathrm{HPA}(\phi)$ was $~ 50 \mathrm{~mol} \%$ from $3 \mathrm{HPA}$ to $3 \mathrm{HP}$ and $1,3 \mathrm{PDO}$, respectively. Subsequently, increasing the feeding rate to $1 \mathrm{~g} / \mathrm{h}$ resulted in the production of $5.98 \mathrm{~g} / \mathrm{L}$ of $3 \mathrm{HP}$, $5.05 \mathrm{~g} / \mathrm{L}$ of $1,3 \mathrm{PDO}$, and accumulation of extracellular 3HPA to $1.36 \mathrm{~g} / \mathrm{L}$ after $10 \mathrm{~h}$ (Figure 3A). The corresponding production rates were $0.40,0.34$ and $0.15 \mathrm{~g} / \mathrm{h}$, respectively.

Using the RPRB3007 strain at pH 5 showed no accumulation of the intermediate 3HPA during fed-batch operation at 0.6 and $1 \mathrm{~g} / \mathrm{h}$ glycerol feeding rates. Complete conversion of glycerol to $6.57 \mathrm{~g} / \mathrm{L} 3 \mathrm{HP}$ and $5.55 \mathrm{~g} / \mathrm{L} 1,3 \mathrm{PDO}$ was achieved. Further increase in the feeding rate to $1.9 \mathrm{~g} / \mathrm{h}$ glycerol between $22.3 \mathrm{~h}$ and $32.3 \mathrm{~h}$ resulted in accumulation of $3 \mathrm{HPA}$ to $1.7 \mathrm{~g} / \mathrm{L}$ at the end of the biotransformation period. The production rates during the last $10 \mathrm{~h}$ of biotransformation were $0.66 \mathrm{~g} / \mathrm{h}$ and $0.78 \mathrm{~g} / \mathrm{h}$ for $1,3 \mathrm{PDO}$ and $3 \mathrm{HP}$, respectively (Figure $3 \mathrm{~B}$ ). The maximum specific production rates obtained with the wild-type and RPRB3007 strains were confirmed by independent experiments where the glycerol feeding rate was maintained at the maximum rate determined for each strain (data not shown), which also revealed that the maximum specific production rates for the products were 2.2 fold higher with the RPRB3007 strain (Table 1).

Increasing the $\mathrm{pH}$ of the biotransformation reaction to 7 resulted in an increase in the specific production rates of $3 \mathrm{HP}$ and 1,3PDO to 110.8 and $93.7 \mathrm{mg} / \mathrm{g}_{\mathrm{CDW}} \cdot \mathrm{h}$ for the wild-type strain, and 179.2 and $151.4 \mathrm{mg} / \mathrm{g}_{\mathrm{CDW}} \cdot \mathrm{h}$ for the RPRB3007 strain, respectively (Figure 3C \& 3D and Table 1). This is in agreement with the reported optimum $\mathrm{pH}$ for the activity of PduP [33], and is also close to the reported optimum $\mathrm{pH}$ of 6.2 for PduQ [50]. In this case, the final titers of $3 \mathrm{HP}$ and 1,3PDO were 10.6 and $9.0 \mathrm{~g} / \mathrm{L}$, respectively.

\section{Implications for the application of $L$. reuteri for production of 3HPA, 3HP and 1,3PDO}

The results described above show that the use of resting cells of $L$. reuteri in combination with a $3 \mathrm{HPA}$ scavenger 

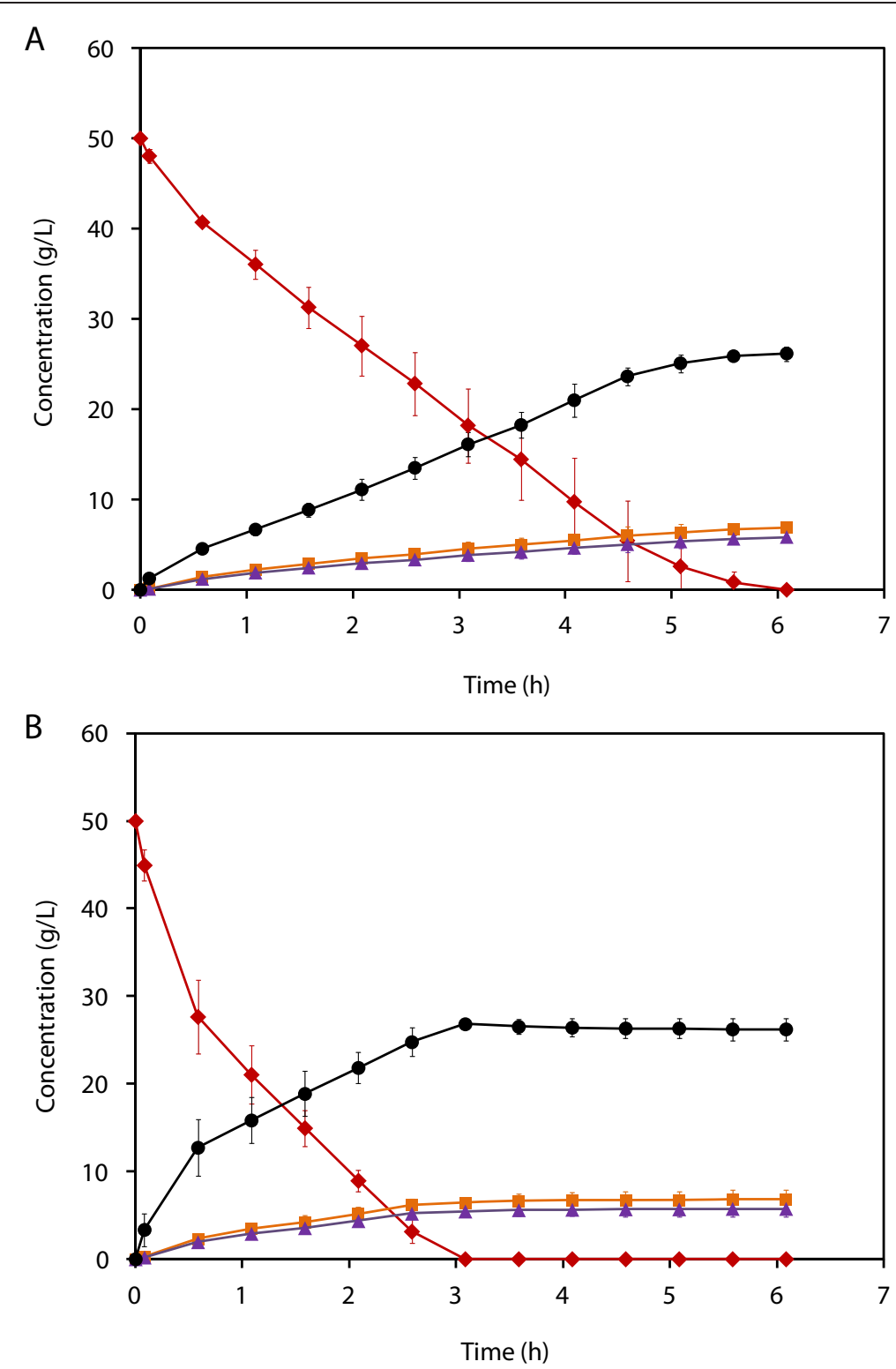

Figure 2 Batch transformation of glycerol using resting cells of $L$. reuteri with in situ 3HPA complexation. Time course for the batch biotransformation of glycerol $(50 \mathrm{~g} / \mathrm{L})$ using resting cells of $\mathrm{L}$. reuteri $(6 \mathrm{gcow} / \mathrm{L})$, wild-type (A) and RPRB3007 (B) in the presence of $50.6 \mathrm{~g} / \mathrm{L}$ carbohydrazide. The concentrations of glycerol $(\bullet), 1,3 \mathrm{PDO}(\mathbf{\Delta}), 3 \mathrm{HPA}(\bullet)$ and $3 \mathrm{HP}(\mathbf{\bullet})$ are shown. Biotransformation (500 $\mathrm{mL}$ working volume) was performed in a 1-L bioreactor under anaerobic conditions at $37^{\circ} \mathrm{C}, 500 \mathrm{rpm}$ and $\mathrm{pH} 7$ (adjusted with $5 \mathrm{~N} \mathrm{NH}_{4} \mathrm{OH}$ ).

under batch mode of operation seems to be a promising approach for 3HPA production. While the RPRB3007 mutant strain with the overexpressed $p d u$ operon exhibited almost two-fold higher specific production rate of 3HPA than the wild-type strain, there is no change in the susceptibility to 3HPA inhibition and requires the presence of the scavenger for aldehyde production. Fed-batch and immobilized-cell configurations have been used with the wild-type strain for the production of 3HPA as a carbohydrazide complex with improved yields [29] and should also be tested with the RPRB3007 strain. Considering the relatively high cost of carbohydrazide, it would also be useful to test other more costeffective scavengers, or to isolate mutants with higher tolerance to 3HPA.

In the experiments for the production of 1,3PDO and $3 \mathrm{HP}$ with resting cells of the wild-type strain, the controlled glycerol feeding strategy allowed their co-production at a higher productivity $\left(0.56 \mathrm{~g}_{1,3 \mathrm{PDO}} / \mathrm{L} . \mathrm{h}\right.$ and $\left.0.66 \mathrm{~g}_{3 \mathrm{HP}} / \mathrm{L} . \mathrm{h}\right)$ compared to that obtained using a recombinant strain of $L$. reuteri lacking glycerol dehydrogenase activity under batch operation (0.06 $\mathrm{g}_{1,3 \mathrm{PDO}} / \mathrm{L} . \mathrm{h}$ and $\left.0.07 \mathrm{~g}_{3 \mathrm{HP}} / \mathrm{L} . \mathrm{h}\right)$ [22]. The 
Table 1 Specific rates for glycerol consumption and 3HPA, 3HP and 1,3PDO production by L. reuteri

\begin{tabular}{|c|c|c|c|c|c|c|c|c|c|c|}
\hline \multirow[t]{4}{*}{ Mode } & \multirow{4}{*}{$\begin{array}{l}\text { Glycerol } \\
\text { feeding } \\
\text { rate }(\mathrm{g} / \mathrm{h})\end{array}$} & \multirow{4}{*}{$\mathrm{pH}$} & \multicolumn{8}{|c|}{ Specific production/consumption rates $\left(\mathrm{mg} / \mathrm{g}_{\mathrm{CDW}} \cdot \mathrm{h}\right)$} \\
\hline & & & \multicolumn{2}{|c|}{ Glycerol $\left(q_{s}\right)$} & \multicolumn{2}{|c|}{$3 \mathrm{HPA}\left(q_{3 H P A}\right)^{[c]}$} & \multicolumn{2}{|l|}{$3 \mathrm{HP}\left(q_{3 н P}\right)$} & \multicolumn{2}{|c|}{$1,3 \mathrm{PDO}\left(q_{1,3 P D O}\right)$} \\
\hline & & & \multicolumn{2}{|l|}{$v_{1}$} & \multicolumn{2}{|c|}{$v_{4}$} & \multicolumn{2}{|l|}{$v_{3}$} & \multicolumn{2}{|c|}{$v_{2}$} \\
\hline & & & $\overline{\text { WT }}$ & M & $\overline{W T}$ & M & $\overline{W T}$ & M & $\overline{\text { WT }}$ & M \\
\hline $\mathrm{B}^{[\mathrm{a}]}$ (overall) & - & 7 & $-1583.2 \pm 204.8$ & $-2842.0 \pm 324.8$ & $889.0 \pm 65.6$ & $1718.2 \pm 98.3$ & $233.8 \pm 43.7$ & $426.5 \pm 40.5$ & $197.5 \pm 36.9$ & $360.3 \pm 34.2$ \\
\hline$B^{[b]}$ (linear) & - & & $-1474.3 \pm 182.8$ & $-2101.3 \pm 252.3$ & $856.2 \pm 79.3$ & $1122.6 \pm 108.8$ & $200.5 \pm 41.2$ & $330.2 \pm 36.1$ & $169.3 \pm 34.8$ & $291.6 \pm 48.4$ \\
\hline \multirow[t]{3}{*}{ FB } & 0.6 & 7 & $-108.0 \pm 1.6$ & $-98.7 \pm 5.8$ & 0 & 0 & $49.3 \pm 3.5$ & $49.8 \pm 1.6$ & $41.7 \pm 3.0$ & $42.1 \pm 1.3$ \\
\hline & 1.6 & & $-266.2 \pm 15.7$ & $-256.9 \pm 3.2$ & $29.0 \pm 5.8$ & 0 & $110.8 \pm 3.0$ & $113.5 \pm 2.3$ & $93.7 \pm 2.5$ & $95.9 \pm 2.0$ \\
\hline & 2.5 & & ND & $-420.8 \pm 5.8$ & ND & $36.2 \pm 2.2$ & ND & $179.2 \pm 5.3$ & ND & $151.4 \pm 4.5$ \\
\hline \multirow[t]{3}{*}{ FB } & 0.6 & 5 & $-101.5 \pm 3.8$ & $-100.5 \pm 2.4$ & 0 & 0 & $43.0 \pm 3.7$ & $49.9 \pm 4.3$ & $36.3 \pm 3.1$ & $42.2 \pm 3.7$ \\
\hline & 1 & & $-150 \pm 18.0$ & $-164.6 \pm 2.2$ & $25.9 \pm 1.2$ & 0 & $62.4 \pm 4.1$ & $76.6 \pm 2.8$ & $52.7 \pm 3.4$ & $64.7 \pm 2.3$ \\
\hline & 1.9 & & ND & $-313.5 \pm 5.3$ & ND & $44.4 \pm 5.1$ & ND & $139.0 \pm 9.4$ & ND & $117.4 \pm 7.9$ \\
\hline
\end{tabular}

${ }^{[\mathrm{a}]}$ Rates for the whole conversion process. ${ }^{[\mathrm{b}]}$ Linear region after $30 \mathrm{~min} .{ }^{[\mathrm{c}]}$ Extracellular $3 \mathrm{HPA}$ accumulation rate.

The specific glycerol consumption rate and 3HPA, 3HP and 1,3PDO production rates using wild-type (WT) and RPRB3007 mutant strain (M) of L. reuteri in batch (B) and variable-volume fed-batch (FB) modes of operation. Values with standard deviations represent the average of two independent replicates.

corresponding rates using the RPRB3007 strain were even higher, $0.91 \mathrm{~g}_{1,3 \mathrm{PDO}} / \mathrm{L} . \mathrm{h}$ and $1.08 \mathrm{~g}_{3 \mathrm{HP}} / \mathrm{L} . \mathrm{h}$. So far, the highest volumetric productivities reported for 1,3PDO and $3 \mathrm{HP}$ were $7.6 \mathrm{~g} / \mathrm{L} . \mathrm{h}$ and $9 \mathrm{~g} / \mathrm{L} . \mathrm{h}$, respectively, obtained using resting cells of recombinant $E$. coli overexpressing the $L$. reuteri genes encoding glycerol dehydratase, its reactivation factor, and 1,3-propanediol oxidoreductase, as well as an E. coli K-12 aldehyde dehydrogenase [22]. In contrast to $L$. reuteri, the absence of protein shells (metabolosomes) in E. coli minimizes the mass transfer limitation of the substrate, intermediates and co-factors, and 3HPA is converted to $3 \mathrm{HP}$ in a single-step reaction.
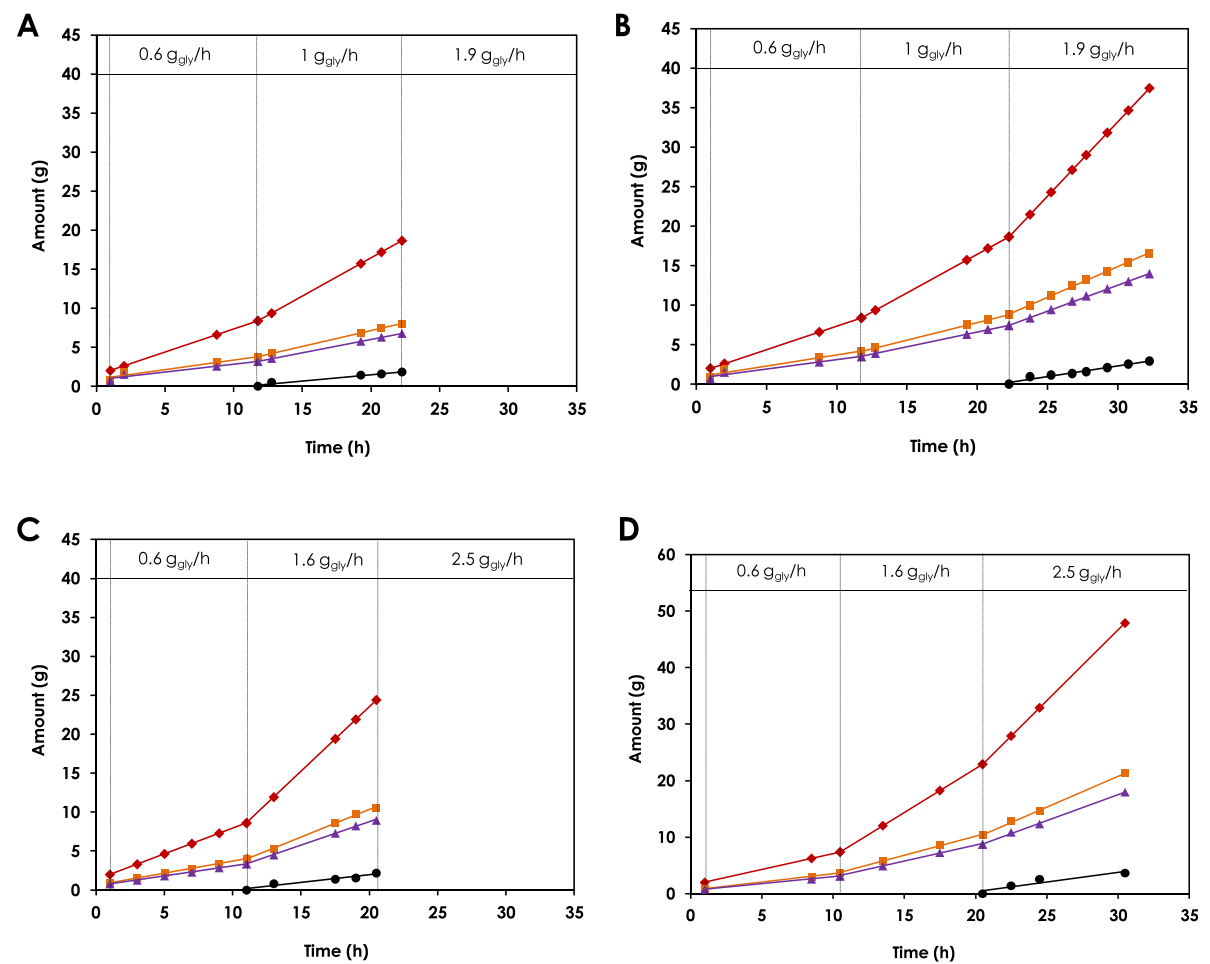

Figure 3 Multi-step variable-volume fed-batch biotransformation of glycerol using resting cells of $L$. reuteri. Multi-step variable-volume fed-batch biotransformation of glycerol using resting cells of wild-type (A \& C) and RPRB3007 (B \& D) strains of L. reuteri (6 gCDw/L). Experiments were conducted at pH 5 (A \& B) and pH 7 (C \& D). After $1 \mathrm{~h}$ of batch biotransformation, glycerol (50 g/L) was fed at a rate of $0.6 \mathrm{ggly} / \mathrm{h}, 1.0 \mathrm{ggly} / \mathrm{h}$ and $1.9 \mathrm{ggly} / \mathrm{h}$, respectively, for determination of the maximum flux through the reductive and oxidative branches of the Pdu pathway at pH 5. The corresponding feeding rates were $0.6 \mathrm{ggly} / \mathrm{h}, 1.6 \mathrm{ggly} / \mathrm{h}$ and $2.5 \mathrm{ggly} / \mathrm{h}$, respectively, at pH 7. Consumed glycerol $(\bullet)$, produced $3 \mathrm{HP}(\boldsymbol{\bullet}), 3 \mathrm{HPA}(\bullet)$ and 1,3PDO $(\mathbf{\Lambda})$ are presented. 
The measured fluxes for the different steps in the Pdu pathway indicate that the rate of glycerol dehydration catalysed by GDH is at least 10 times faster than the subsequent reduction or oxidation of 3HPA to 1,3PDO and $3 \mathrm{HP}$, respectively (Table 1 ). Hence for targeting the coproduction of $3 \mathrm{HP}$ and 1,3PDO, the glycerol feeding rate should be controlled to maintain the flux $v_{1} \leq\left(v_{2}+v_{3}\right)$. When the glycerol feeding rate is $\geq v_{1}$, 3HPA is accumulated as the main end product. MFA further suggests that the oxidative and/or reductive pathways could be critical targets for further metabolic engineering towards enhanced production of 3HP and 1,3PDO. Further metabolic engineering of the RPRB3007 strain could help in reducing the product inhibition, and improving the volumetric productivity and yield. Since the Pdu pathway is a non-growth associated pathway, metabolic engineering for enhanced production of 3HPA, 3HP and 1,3PDO is possible without interference with microbial growth. There seems to be no need for knocking out the gene encoding for glycerol dehydrogenase as done by Yasuda et al. [22], since no DHA production was observed in our experiments.

Despite the low volumetric productivity, there are many other factors that make the $L$. reuteri-based process desirable. The high purity of the resulting product mixture obtained using resting cells (Figure 4), greatly simplifies the downstream processing and minimizes production costs. In the process using recombinant strain of $K$. pneumonia, part of the glycerol is converted to dihydroxyacetone phosphate, which then enters the glycolytic pathway yielding lactic acid, acetic acid and other alcohols as the main by-products. In a study using recombinant Pseudomonas denitrificans, 3HP was further oxidized to malonate and utilized for cell growth resulting in decreased yield. Several by-products (lactic acid, succinic acid, acetic acid, ethanol and others) were indeed obtained as a result of glucose metabolism when the growing cells of $L$. reuteri were used (data not shown), which would lead to complicated downstream processing and increased costs even if the concentrations, volumetric- and specific production rates of 1,3PDO and 3HP were higher than those obtained using resting cells. The use of resting cells also makes process operation very simple, and moreover both the wild-type and RPRB3007 strains do not need to be grown in media with antibiotics that reduces operational costs.

Further studies to determine the extent of recyclability of the microbial biocatalyst as well as the maximum concentration of the two final products that can be tolerated are in progress.

\section{Conclusions}

L. reuteri has great potential as a candidate for the industrial production of 3HPA, 3HP and 1,3PDO. The strain is amenable to metabolic engineering and a wide variety of methods for its genetic manipulation are available. Engineering of the $p d u$ operon to increase the glycerol-utilization rate is a good strategy to increase specific production rates, and further manipulation could render a robust strain for industrial applications. This study presents a useful method for determination of metabolic fluxes of the Pdu pathway in L. reuteri with glycerol as substrate. The method not only provided a stepping stone for developing a production process for $3 \mathrm{HPA}$ or co-production of $3 \mathrm{HP}$ and 1,3PDO using whole resting cells of $L$. reuteri but also shed some light on important aspects to consider during process design to allow for cleaner production.

\section{Methods}

Materials

Glycerin Tech $^{\odot}$ (98\%), a co-product of biodiesel production, and standard 3-hydroxypropionic acid (30\% w/v) were provided by Perstorp AB, Sweden. Lactobacilli MRS broth

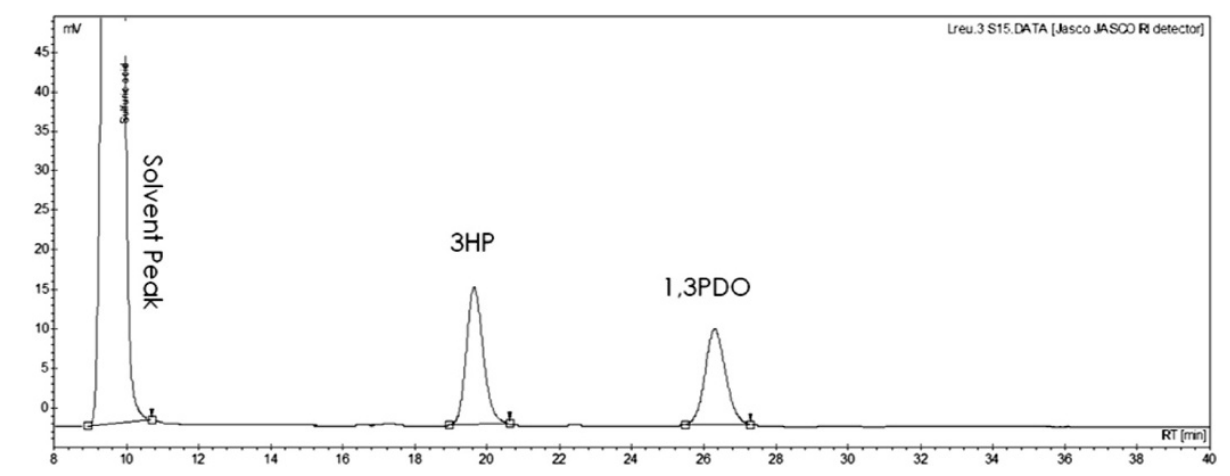

Figure 4 Chromatographic profiles for $3 \mathrm{HP}$ and 1,3PDO production using resting cells of $L$. reuteri. Chromatographic profile for the different products formed during transformation of glycerol to $3 \mathrm{HP}$ and 1,3PDO using cells of wild-type L. reuteri under resting conditions. The biotransformation conditions and the composition of the feeding solutions are described in the Methods section. 
(containing per liter: $10 \mathrm{~g}$ protease peptone, $10 \mathrm{~g}$ beef extract, 5 g yeast extract, 20 g dextrose, $1 \mathrm{~g}$ Tween 80, 2 g ammonium citrate, $5 \mathrm{~g}$ sodium acetate, $0.1 \mathrm{~g}$ magnesium sulfate, $0.05 \mathrm{~g}$ manganese sulfate and $2 \mathrm{~g}$ dipotassium phosphate) was a product of Difco (BD laboratories, Detroit, Michigan, USA). 1,3-Propanediol (99\%) was obtained from Sigma-Aldrich (St Louis, MO, USA), glucose monohydrate from Prolabo (VWR International, Fontenay-sous-Bois, France), and 1,2-propanediol (1,2PDO) was from Merck (NJ, USA).

\section{Microorganisms and culture conditions}

L. reuteri DSM 20016 and L. reuteri RPRB3007 with a modification in the catabolite repression element (CRE) upstream of the $p d u$ operon [39], were used for the biotransformation of glycerol. Inocula were grown in 30-mL serum bottles containing $20 \mathrm{~mL} 55 \mathrm{~g} / \mathrm{L}$ MRS and $20 \mathrm{mM}$ 1,2-propanediol. The medium was added to the bottles, boiled, and bubbled with nitrogen gas. The bottles were then closed with rubber stoppers, and autoclaved at $121^{\circ} \mathrm{C}$ for $15 \mathrm{~min}$. The sterilized medium was inoculated with $200 \mu \mathrm{L}$ of a stock culture in $20 \% \mathrm{v} / \mathrm{v}$ glycerol and then incubated at $37^{\circ} \mathrm{C}$ for $16 \mathrm{~h}$. Two hundred microliters of the resulting culture were transferred to $20 \mathrm{~mL}$ of fresh medium and incubated for $8 \mathrm{~h}$ under the same conditions. The resulting culture was used as inoculum in bioreactor studies.

\section{Production of the whole-cell biocatalyst for biotransformation of glycerol}

L. reuteri cells were grown in a 3-L bioreactor (Applikon, Microbial Biobundle, The Netherlands). Monitoring and control of all the parameters was done through an $e z$ control unit. Stirrer speed was maintained at $200 \mathrm{rpm}$, temperature at $37^{\circ} \mathrm{C}$ and $\mathrm{pH}$ at 5.5 by addition of $5 \mathrm{~N}$ $\mathrm{NH}_{4} \mathrm{OH}$. Anaerobic conditions were maintained through continuous bubbling of nitrogen gas. Twenty milliliters of the freshly prepared inoculum were aseptically added to 2-L fermentation medium containing $55 \mathrm{~g} / \mathrm{L}$ MRS broth, $5 \mathrm{~g} / \mathrm{L}$ 1,2-propanediol, and glucose at a final concentration of $40 \mathrm{~g} / \mathrm{L}$. Fermentation was conducted for $10 \mathrm{~h}$ after which the broth was collected and centrifuged at $15000 \times \mathrm{g}$ and $4^{\circ} \mathrm{C}$ for 5 minutes. The supernatant was discarded and the cell pellet was used for the biotransformation of glycerol.

\section{Batch production of 3HPA from glycerol using resting cells of $L$. reuteri}

Biotransformation of glycerol was done in a 1-L Biostat ${ }^{\circ}-\mathrm{Q}$ bioreactor (B. Braun Biotech International, Melsungen, Germany) with a $0.5-\mathrm{L}$ working volume. The process was started by resuspending the $L$. reuteri cells obtained as described above, in $0.5 \mathrm{~L}$ solution containing $50 \mathrm{~g} / \mathrm{L}$ glycerol and $50.6 \mathrm{~g} / \mathrm{L}$ carbohydrazide to a final cell density of $6 \mathrm{~g}_{\mathrm{CDW}} / \mathrm{L}$. Glycerol biotransformation was performed at $37^{\circ} \mathrm{C}, \mathrm{pH} \mathrm{7,500} \mathrm{rpm}$, with continuous nitrogen bubbling to maintain anaerobic conditions. Samples were collected and analyzed for glycerol, 3HP, 1,3PDO, and $3 \mathrm{HPA}$, and the experiment was stopped when all the glycerol had been consumed.

The biotransformation kinetics were determined using the following equations:

$$
\begin{aligned}
& \text { - Volumetric production rate, } Q_{p}(g / L \cdot h)=\left[P_{\text {final }}-P_{\text {initial }}\right] / \Delta t \\
& \text { - Volumetric consumption rate, } Q_{s}(g / L . h)=\left[S_{\text {final }}-S_{\text {initial }}\right] / \Delta t \\
& \text { - Specific production rate, } q_{p}\left(\mathrm{mg} / g_{C D W} \cdot h\right)=Q_{p} \cdot 1000 / X \\
& \text { - Specific consumption rate, } q_{s}\left(\mathrm{mg} / \mathrm{g}_{C D W} \cdot h\right)=Q_{s} \cdot 1000 / X
\end{aligned}
$$

where $P$ and $S$ are the concentrations of the products and substrate $(\mathrm{g} / \mathrm{L})$, respectively, $X$ is the cell density $\left(\mathrm{g}_{\mathrm{CDW}} / \mathrm{L}\right)$, and $\Delta t$ is the time elapsed between the initial and final conditions (h).

\section{Fed-batch production of 1,3PDO and 3HP from glycerol using resting cells of $L$. reuteri}

Biotransformation of glycerol was done in a 3-L bioreactor (Applikon, The Netherlands) with a 1-L initial working volume. The process was started by resuspending the harvested $L$. reuteri cells from the biocatalystproduction step in a $1-\mathrm{L}$ solution containing $2 \mathrm{~g} / \mathrm{L}$ glycerol to a final density of $6 \mathrm{~g}_{\mathrm{CDW}} / \mathrm{L}$. After $1 \mathrm{~h}$ of batch biotransformation, fed-batch mode was started by feeding glycerol $(50 \mathrm{~g} / \mathrm{L})$ at a rate of $12 \mathrm{~mL} / \mathrm{h}\left(0.6 \mathrm{~g}_{\mathrm{gly}} / \mathrm{h}\right)$ for $10 \mathrm{~h}$. Subsequently, the feeding rate was increased to $31.1 \mathrm{~mL} / \mathrm{h}\left(1.6 \mathrm{~g}_{\mathrm{gly}} / \mathrm{h}\right)$ for $10 \mathrm{~h}$, and finally to $50 \mathrm{~mL} / \mathrm{h}$ $\left(2.5 \mathrm{~g}_{\mathrm{gly}} / \mathrm{h}\right)$ for $10 \mathrm{~h}$. The biotransformation was per-

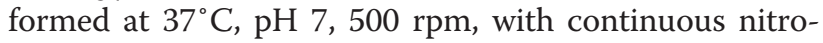
gen bubbling to maintain anaerobic conditions. The $\mathrm{pH}$ was chosen based on the reported optimum for some of the enzymes of the Pdu pathway [34,50].

Since some studies for 1,3PDO production in $L$. reuteri have used acidic $\mathrm{pH}$ conditions, the experiment was also conducted at $\mathrm{pH} 5$ [51]. In this case, the feeding rates and feeding periods were $12 \mathrm{~mL} / \mathrm{h}\left(0.6 \mathrm{~g}_{\text {gly }} / \mathrm{h}\right)$ for $11 \mathrm{~h}$, $19.8 \mathrm{~mL} / \mathrm{h}\left(1 \mathrm{~g}_{\mathrm{gly}} / \mathrm{h}\right)$ for $10 \mathrm{~h}$, and $38.1 \mathrm{~mL} / \mathrm{h}\left(1.9 \mathrm{~g}_{\mathrm{gly}} / \mathrm{h}\right)$ for $10 \mathrm{~h}$.

The feeding rates were determined according to a preliminary fed-batch experiment at a constant feeding rate. The feeding time $(10 \mathrm{~h})$ was chosen to ensure the stability of the measured fluxes before shifting to a higher feeding rate.

Samples were collected frequently and analyzed for glycerol, 3HP, 3HPA and 1,3PDO concentrations. The 
biotransformation kinetics were determined for each step (feeding rate) using the following equations:

$$
\begin{aligned}
& -\operatorname{Production} \operatorname{rate}(g / h)=\left[\left(P_{\text {final }} \cdot V_{\text {final }}\right)-\left(P_{\text {initial }} \cdot V_{\text {initial }}\right)\right] / \Delta t \\
& \text { - Consumption rate }(g / h)=\left[\left(S_{\text {final }} \cdot V_{\text {final }}\right)-\left(\left(S_{\text {feed }} \cdot V_{\text {feed }}\right)\right.\right. \\
& \left.\left.+\left(S_{\text {initial }} \cdot V_{\text {initial }}\right)\right)\right] / \Delta t \\
& \text { - Specific production rate, } q_{P}\left(m g / g_{C D W} \cdot h\right)=\text { production rate }(g / h) \cdot 1000 / x \\
& \text { - Specific consumption rate, } q_{S}\left(m g / g_{C D W} \cdot h\right)=\text { consumption rate }(g / h) \cdot 1000 / x
\end{aligned}
$$

where $P$ and $S$ are the concentrations of the products and substrate $(\mathrm{g} / \mathrm{L})$, respectively, $V$ is the reaction volume, $x$ is the amount of the biocatalyst $\left(\mathrm{g}_{\mathrm{CDW}}\right)$, and $\Delta t$ is the time elapsed between the initial and final conditions (h).

\section{Analytical procedures}

Cell growth was monitored by measuring optical density at $620 \mathrm{~nm}$ using a Ultrospec 1000 spectrophotometer (Pharmacia Biotech, Uppsala, Sweden) and then correlated with cell dry weight (CDW). For determination of the cell dry weight, $10 \mathrm{~mL}$ of the culture broth were centrifuged at $3893 \times \mathrm{g}$ for 20 minutes in a pre-dried $\left(105^{\circ} \mathrm{C}\right.$ for $\left.2 \mathrm{~h}\right)$, pre-weighed $15 \mathrm{~mL}$ tube. The supernatant was removed and the cell pellet was dried at $105^{\circ} \mathrm{C}$ overnight and then weighed again. The difference in weight is equivalent to cell dry weight in $10 \mathrm{~mL}$ culture.

Glycerol, glucose, lactic acid, ethanol, acetic acid, 1,2-propanediol, propionaldehyde, propionic acid, 3HP, and 1,3PDO concentrations were determined by HPLC (JASCO, Tokyo, Japan) equipped with RI detector (ERC, Kawaguchi, Japan), a JASCO UV detector and a JASCO intelligent autosampler. Separation of the compounds was done on an Aminex HPX-87H chromatographic column connected to a guard column (Biorad, Richmond, CA, USA). The column temperature was maintained at $65^{\circ} \mathrm{C}$ in a chromatographic oven (Shimadzu, Tokyo, Japan). Samples from the bioreactor were diluted with Milli- $Q$ quality water and mixed with $20 \% \mathrm{v} / \mathrm{v}$ sulfuric acid (20 $\mu \mathrm{L} / \mathrm{mL}$ sample) and then filtered. A forty-microliter aliquot was injected in $0.5 \mathrm{mM} \mathrm{H}_{2} \mathrm{SO}_{4}$ mobile phase flowing at a rate of $0.4 \mathrm{~mL} / \mathrm{min}$. The retention times $(\mathrm{min})$ for the different compounds were 13.890 (glucose), 18.317 (lactic acid), 19.500 (3HP), 20.208 (glycerol), 22.350 (acetic acid), 25.400 (1,2-propanediol), 25.876 (propionic acid), 26.400 (1,3PDO), 32.858 (ethanol), 33.290 (propionaldehyde) and $40.100 \mathrm{~min}$ (n-propanol).

For the determination of 3HPA concentration, a modified colorimetric method of Circle et al. (1945) [52] as described by Ulmer and Zeng (2007) [53] with acrolein as standard was used. Briefly, $1 \mathrm{~mL}$ of sample (diluted to be within the range of the assay) was mixed with $750 \mu \mathrm{L}$ of $10 \mathrm{mMDL}$-tryptophan solution in $50 \mathrm{mM} \mathrm{HCl}$ and
$3 \mathrm{~mL}$ of concentrated $\mathrm{HCl}$ (fuming 37\%). The reaction mixture was incubated for $20 \mathrm{~min}$ at $37^{\circ} \mathrm{C}$, and the resulting purple color was then measured spectrophotometrically at $560 \mathrm{~nm}$.

\section{Statistical analysis}

The represented kinetics are the average of two independent replicates \pm standard deviation. The significance of the results was calculated using the Students' T-test with $\mathrm{P}<0.05$ (95\% significance).

\section{Competing interests}

The authors declare that they have no competing interests.

\section{Authors' contributions}

TD and LPP designed and performed the laboratory experiments and data analysis as well as prepared the first draft of the manuscript. RAB provided the RPRB3007 strain. RHK, RAB and SHP contributed in the formulation of the idea and the revision of the manuscript. All authors read and approved the final manuscript.

\section{Acknowledgements}

The Swedish Governmental Agency for Innovation Systems (VINNOVA) is thanked for financing the project. Perstorp $A B$ is acknowledged for coordinating the project.

\section{Author details}

'Department of Biotechnology, Center for Chemistry and Chemical Engineering, Lund University, SE-221 00 Lund, Sweden. ²Department of Microbiology and Molecular Genetics, Michigan State University, East Lansing, Michigan, USA.

Received: 24 January 2014 Accepted: 14 May 2014 Published: 27 May 2014

\section{References}

1. Jong E, Higson A, Walsh P, Wellisch M, Barbosa M, Blaauw R, Gosselink R, Ree $\mathrm{R}$, Jorgensen $\mathrm{H}$, Mandl M, McLaughlin M, Smith MA, Willke T: Value Added Products from Biorefineries. 2012. Report prepared on behalf of IEA Bioenergy, Task 42 Biorefinery.

2. Werpy T, Petersen G, Aden A, Bozell J, Holladay J, White J, Manheim A, Elliot D, Lasure L, Jones S, Gerber M, Ibsen K, Lumberg L, Kelley S: Top Value Added Chemicals from Biomass, Volume 1-Results of Screening for Potential Candidates from Sugars and Synthesis Gas. Oak Ridge, TN: U.S. Department of Energy; 2004. available at www.eere.energy.gov/biomass/pdfs/35523.pdf

3. Vollenweider S, Lacroix C: 3-Hydroxypropionaldehyde: applications and perspectives of biotechnological production. Appl Microbiol Biotechnol 2004, 64:16-27.

4. Kumar V, Ashok S, Park S: Recent advances in biological production of 3-hydroxypropionic acid. Biotechnol Adv 2013, 31:945-961.

5. Haas T, Yu D, Sauer J, Arntz D, Freund A, Tacke T: Process for the Production of 1,3-proapendiol by Hydrogenating 3-Hydroxypropionaldehyde; 1998. WO 1998057913 A1.

6. Powell JB, Mullin SB, Weider PR, Eubanks DC, Arhancet JP: Process for Preparing 1,3-propanediol. 1998. US Patent 5770776.

7. Bauer R, du Toit M, Kossmann J: Influence of environmental parameters on production of the acrolein precursor 3-hydroxypropionaldehyde by Lactobacillus reuteri DSMZ 20016 and its accumulation by wine lactobacilli. Int J Food Microbiol 2010, 137:28-31.

8. Ulmer C, Deckwer WD, Zeng AP: Zweistufiger prozess zur herstellung von 1,3-propandiol und 3-hydroxypropionaldehyd aus glycerin. Chem-Ing-Tech 2002, 74:674.

9. Lüthi-Peng Q, Scharer S, Puhan Z: Production and stability of 3-hydroxypropionaldehyde in Lactobacillus reuteri. Appl Microbiol Biotechnol 2002, 60:73-80

10. Della Pina C, Falletta E, Rossi M: A green approach to chemical building blocks. The case of 3-hydroxypropanoic acid. Green Chem 2011, 13:1624-1632. 
11. Lilga MA, White JF, Holladay JE, Zacher AH, Muzatko DS, Orth RJ: Method for Conversion of $\beta$-hydroxy Carbonyl Compounds. 2010. US Patent 7687661.

12. Banner T, Fosmer A, Jessen H, Marasco E, Rush B, Veldhouse J, De Souza M: Microbial bioprocesses for industrial-scale chemical production. In Biocatalysis for Green Chemistry and Chemical Process Development. John Wiley \& Sons, Inc: Tao J and Kazlauskas R. Hoboken, NJ; 2011:429-467.

13. Zeng A-P, Biebl H: Bulk chemicals from biotechnology: the case of 1,3propanediol production and the new trends. In Advances in Biochemical Engineering/Biotechnology, Volume 74. New York: Springer Berlin Heidelberg: Scheper T, Schügerl K, Zeng A-P; 2002:239-259.

14. Steverding D: Mikrobielle herstellung von 1,3-propandiol. fermentative biotechnologie. Chem Unserer Zeit 2010, 44:384-389.

15. Werle P, Morawietz M, Lundmark S, Sörensen K, Karvinen E, Lehtonen J: Alcohols, polyhydric. In Ullmann's Encyclopedia of Industrial Chemistry, Volume 2. Wiley-VCH Verlag GmbH \& Co. KGaA: Weinheim; 2000:263-284.

16. Nakamura CE, Gatenby AA, Hsu AK-h, La Reau RD, Haynie SL, Diaz-torres M, Trimbur DE, Whited GM, Nagarajan V, Payne MS, Picataggio SK, Nair RV: Method for the Production of 1,3-propanediol by Recombinant Microorganisms; 2000. US Patent 6013494

17. BASF, Cargill and Novozymes Achieve Milestone in Bio-based Acrylic Acid Process. [www.basf.com/group/pressrelease/P-13-356]

18. Mirasol F: Chemical profile: Biodiesel. In ICIS Chemical Business. 2009.

19. Statistics - EU biodiesel industry. [http://www.ebb-eu.org/stats.php]

20. Agarwal GP: Glycerol. In Microbial Bioproducts. Edited by Fiechter A. New York: Springer Berlin Heidelberg: [Scheper T, Belkin S, Doran PM, Endo I, Gu MB, Hu WS, Mattiasson B, Nielsen J, Stephanopoulos GN, Ulber R, Zeng A-P, Zhong J-J, Zhou W, Harald S (Series Editors): Advances in Biochemical Engineering/Biotechnology, vol 41.]; 1990:95-128.

21. Wang ZX, Zhuge J, Fang HY, Prior BA: Glycerol production by microbial fermentation: A review. Biotechnol Adv 2001, 19:201-223.

22. Yasuda S, Mukoyama M, Horikawa H, Toraya T, Morita H: Process for Producting 1,3-propanediol and or/3-hydroxypropionic Acid. 2007. US Patent 20070148749 A1.

23. Zhu JG, Ji XJ, Huang H, Du J, Li S, Ding YY: Production of 3-hydroxypropionic acid by recombinant Klebsiella pneumoniae based on aeration and ORP controlled strategy. Korean J Chem Eng 2009, 26:1679-1685.

24. Ashok S, Raj SM, Rathnasingh C, Park S: Development of recombinant Klebsiella pneumoniae $\Delta d h a T$ strain for the co-production of 3hydroxypropionic acid and 1,3-propanediol from glycerol. Appl Microbiol Biot 2011, 90:1253-1265.

25. Huang Y, Li Z, Shimizu K, Ye Q: Simultaneous production of 3-hydroxypropionic acid and 1,3-propanediol from glycerol by a recombinant strain of Klebsiella pneumoniae. Bioresour Technol 2012, 103:351-359.

26. Kumar V, Sankaranarayanan M, Durgapal M, Zhou S, Ko Y, Ashok S, Sarkar R, Park S: Simultaneous production of 3-hydroxypropionic acid and 1,3-propanediol from glycerol using resting cells of the lactate dehydrogenase-deficient recombinant Klebsiella pneumoniae overexpressing an aldehyde dehydrogenase. Bioresour Technol 2013, 135:555-563.

27. Jiang XL, Meng X, Xian M: Biosynthetic pathways for 3-hydroxypropionic acid production. Appl Microbiol Biot 2009, 82:995-1003.

28. Sardari RRR, Dishisha T, Pyo SH, Hatti-Kaul R: Improved production of 3-hydroxypropionaldehyde by complex formation with bisulfite during biotransformation of glycerol. Biotechnol Bioeng 2013, 110:1243-1248.

29. Krauter H, Willke T, Vorlop K-D: Production of high amounts of 3-hydroxypropionaldehyde from glycerol by Lactobacillus reuteri with strongly increased biocatalyst lifetime and productivity. New Biotechnol 2012, 29:211-217.

30. Sardari RRR, Dishisha T, Pyo S-H, Hatti-Kaul R: Biotransformation of glycerol to 3-hydroxypropionaldehyde: Improved production by in situ complexation with bisulfite in a fed-batch mode and separation on anion exchanger. J Biotechnol 2013, 168:534-542.

31. Talarico TL, Casas IA, Chung TC, Dobrogosz WJ: Production and isolation of reuterin, a growth inhibitor produced by Lactobacillus reuteri. Antimicrob Agents Chemother 1988, 32:1854-1858.

32. Raj SM, Rathnasingh C, Jo JE, Park S: Production of 3-hydroxypropionic acid from glycerol by a novel recombinant Escherichia coli BL21 strain. Process Biochem 2008, 43:1440-1446.

33. Sriramulu DD, Liang M, Hernandez-Romero D, Raux-Deery E, Lunsdorf H, Parsons JB, Warren MJ, Prentice MB: Lactobacillus reuteri DSM 20016 produces cobalamin-dependent diol dehydratase in metabolosomes and metabolizes 1,2-propanediol by disproportionation. J Bacterio/ 2008, 190:4559-4567.
34. Sabet-Azad R, Linares-Pasten JA, Torkelson L, Sardari RRR, Hatti-Kaul R: Coenzyme A-acylating propionaldehyde dehydrogenase (PduP) from Lactobacillus reuteri: Kinetic characterization and molecular modeling. Enzyme Microb Technol 2013, 53:235-242.

35. Stephanopoulos G: Metabolic Fluxes and Metabolic Engineering. Metab Eng 1999, 1:1-11.

36. Stephanopoulos GN, Aristidou AA, Nielsen J: Metabolic Engineering: Principles and Methodologies. San Diego, CA: Academic Press; 1998

37. van Gulik WM, de Laat WTAM, Vinke JL, Heijnen JJ: Application of metabolic flux analysis for the identification of metabolic bottlenecks in the biosynthesis of penicillin-G. Biotech Bioeng 2000, 68:602-618.

38. Kerfeld CA, Heinhorst S, Cannon GC: Bacterial Microcompartments. Annu Rev Microbiol 2010, 64:391-408.

39. van Pijkeren J-P, Neoh KM, Sirias D, Findley AS, Britton RA: Exploring optimization parameters to increase ssDNA recombineering in Lactococcus lactis and Lactobacillus reuteri. Bioengineered 2012, 3:209-217.

40. Stevens MJA, Vollenweider S, Meile L, Lacroix C: 1,3-Propanediol dehydrogenases in Lactobacillus reuteri: impact on central metabolism and 3-hydroxypropionaldehyde production. Microb Cell Fact 2011, 10:61-69.

41. Lüthi-Peng Q, Dileme FB, Puhan Z: Effect of glucose on glycerol bioconversion by Lactobacillus reuteri. Appl Microbiol Biot 2002, 59:289-296.

42. Luo LH, Seo JW, Baek JO, Oh BR, Heo SY, Hong WK, Kim DH, Kim CH: Identification and characterization of the propanediol utilization protein PduP of Lactobacillus reuteri for 3-hydroxypropionic acid production from glycerol. Appl Microbiol Biot 2011, 89:697-703.

43. van Maris AJA, Konings WN, van Dijken JP, Pronk JT: Microbial export of lactic and 3-hydroxypropanoic acid: implications for industrial fermentation processes. Metab Eng 2004, 6:245-255.

44. Toraya T: Radical catalysis in coenzyme B12-dependent isomerization (eliminating) reactions. Chem Rev 2003, 103:2095-2127.

45. Arskold E, Lohmeler-Vogel E, Cao R, Roos S, Radstrom P, van Niel EWJ: Phosphoketolase pathway dominates in Lactobacillus reuteri ATCC 55730 containing dual pathways for glycolysis. J Bacteriol 2008, 190:206-212.

46. Morita H, Toh H, Fukuda S, Horikawa H, Oshima K, Suzuki T, Murakami M, Hisamatsu S, Kato Y, Takizawa T, Fukuoka H, Yoshimura T, Itoh K, O'Sullivan DJ, McKay LL, Ohno H, Kikuchi J, Masaoka T, Hattori M: Comparative genome analysis of Lactobacillus reuteri and Lactobacillus fermentum reveal a genomic island for reuterin and cobalamin production. DNA Res 2008, 15:151-161.

47. Cie A, Lantz S, Schlarp R, Tzakas M: Senior design reports (CBE): Renewable acrylic acid; 2012. Working paper. University of Pennsylvania Available at: http://repository.upenn.edu/cbe_sdr/37/.

48. Chen P, Andersson DI, Roth JR: The control region of the $p d u / c o b$ regulon in Salmonella typhimurium. J Bacteriol 1994, 176:5474-5482.

49. Doleyres Y, Beck P, Vollenweider S, Lacroix C: Production of 3-hydroxypropionaldehyde using a two-step process with Lactobacillus reuteri. Appl Microbiol Biot 2005, 68:467-474.

50. Talarico TL, Axelsson LT, Novotny J, Fiuzat M, Dobrogosz WJ: Utilization of glycerol as a hydrogen acceptor by Lactobacillus reuteri: purification of 1,3-propanediol:NAD oxidoreductase. Appl Environ Microb 1990, 56:943-948.

51. El-Ziney MG, Arneborg N, Uyttendaele M, Debevere J, Jakobsen M: Characterization of growth and metabolite production of Lactobacillus reuteri during glucose/glycerol cofermentation in batch and continuous cultures. Biotechnol Lett 1998, 20:913-916.

52. Circle SJ, Stone L, Boruff CS: Acrolein determination by means of tryptophane: a colorimetric micromethod. Ind Eng Chem 1945, 17:259-262

53. Ulmer C, Zeng AP: Microbial production of 3-hydroxypropionaldehyde from glycerol bioconversion. Chem Biochem Eng Q 2007, 21:321-326.

\section{doi:10.1186/1475-2859-13-76}

Cite this article as: Dishisha et al.: Flux analysis of the Lactobacillus reuteri propanediol-utilization pathway for production of 3hydroxypropionaldehyde, 3-hydroxypropionic acid and 1,3-propanediol from glycerol. Microbial Cell Factories 2014 13:76. 